\title{
Male-attracting Substance in Marine Brown Alage the Genus Dictyopteris
}

\author{
Tadahiko KaJIWARA $^{* 1}$, Kazuya Kodama ${ }^{* 2}$, and Akikazu HatanaKA*1 \\ (Received February 14, 1980)
}

\begin{abstract}
The occurrence of ectocarpene, which is the attractant of male-gamete excreted by the female gametes of the brown marine alga Ectocarpus siliculosus, was first confirmed by the odoriferous essential oils of Dictyopteris prolifera and Dictyopteris undulata.

The "ocean smell" of the essential oils from both species of Japanese Dictyopteris, consisted of mainly non-isoprenoids $C_{11}$-hydrocarbons [dictyopterenes ( $A, B$ and $C^{\prime}$ ) and ectocarpene]. In striking contrast to $D$. prolifera, the constituents of "beach odor" from Dictyopteris divaricata were sesquiterpenes (hydrocarbons) instead of the non-isoprenoids (hydrocarbons).
\end{abstract}

In the previous paper ${ }^{1}$, sarohornene and the isomers were identified as the attractants of malegamete of a marine brown alga Sargassum horneri.

Earlier, MüLler et al. had identified ectocarpene $^{2)},(S)-(+)-6-($ cis-but-1-enyl)-cyclohepta-2, 5dine, as the male-attracting substance of the odoriferous oil from female cultures of the marine brown alga Ectocarpus siliculosus. The pheromone, ectocarpene, was isolated also from $\mathrm{Ha}$ waiian Dictyopteris ${ }^{3}$.

This paper describes the occurrence of ectocarpene and dictyopterenes in Dictyopteris prolifera and $D$. undulata, and sesquiterpenes in D. divaricata.

\section{Materials and Methods}

Dictyopteris divaricata was collected at Funka bay, Muroran, Hokkaido in early June, and $D$. prolifera and $D$. undulata at Yoshimo, Shimonoseki, Yamaguchi at the end of September.

Freshly collected, wet brown seaweeds $D$. prolifera $(83 \mathrm{~g}), D$. undulata $(93 \mathrm{~g})$ and $D$. divaricata $(380 \mathrm{~g})$ were extracted with $n$-pentane saturated with methanol. The pentane layer were separated and the solvents were evaporated to give $1.3 \mathrm{~g}$, $0.8 \mathrm{~g}$ and $3.1 \mathrm{~g}$ of essential oils, respectively. These essential oils were chromatographed on an alumina column (200 mesh activated for column chromatography, Wako Pure Chemical Ind. Ltd.; eluent, $n$-pentane). The pentane eluates were carefully concentrated, and the concentrates were rechromatographed on a silica-gel column (100 mesh
Mallinckrodt Chemical Co. analytical reagent; eluent, $n$-pentane) to give $0.6 \mathrm{~g}, 0.5 \mathrm{~g}$ and $1.2 \mathrm{~g}$ of odoriferous essential oils, respectively.

The infrared spectra (a Hitachi EPI-G2 grating infrared spectrophotometer) of these odoriferous essential oils showed that these consisted of unsaturated hydrocarbons. These hydrocarbons were further characterized by GLC (condition-a : $3 \mathrm{~m} \times$ $3 \mathrm{~mm}$ column of $5 \%$ PEG $20 \mathrm{M}$ on Shimalite W; column temp., $90^{\circ} \mathrm{C}$; injector temp., $120^{\circ} \mathrm{C} ; \mathrm{N}_{2}$ flow rate, $60 \mathrm{~m} / / \mathrm{min}$ and condition-b: $2 \mathrm{~m} \times 4 \mathrm{~mm}$ glass column of $10 \%$ Silicone GE-SE-30 on Chromosorb $\mathrm{W}$; column temp., $80^{\circ} \mathrm{C}-160^{\circ}, 2^{\circ} \mathrm{C} / \mathrm{min}$; injector temp., $200^{\circ} \mathrm{C} ; \mathrm{N}_{2}$ flow rate, $60 \mathrm{~m} / / \mathrm{min}$ ). Some peaks were identified by comparison of their mass spectra (a Hitachi M- 60 at $70 \mathrm{eV}$ with ion source temp. $140^{\circ} \mathrm{C}$ ) and retention data with those of authentic compounds synthesized through unequivocal routes $^{4) * 3}$ and authentic sesquiterpenes.

\section{Results and Discussion}

The characteristic odoriferous oils from freshly wet $D$. prolifera, $D$. undulata and $D$. divaricata, were found to be a mixture of sesquiterpenes and/or non-isoprenoids $C_{11}$-hydrocarbons by combined GLC-mass spectrometry as shown in Fig. 1 and Table 1.

Retention data and mass spectra of Peaks-4 in Fig. 1 were consistent with those of ectocarpene synthesized through unequivocal routes ${ }^{4)}$ as shown in Fig. 2 and Table 1.

Thus, the occurrence of the male-gamete at-

*1 Department of Agricultural Chemistry, Faculty of Agriculture, Yamaguchi University, Yamaguchi 753, Japan（梶原忠应・烟中影和：山口大学费学部典芸化学科).

*2 Research Laboratory, Kaken Drug Co., Ltd., Tokyo 181, Japan (小玉一㦲：化研生薬).

* T. Kajtwara, T. Nakatomi, Y. Sasaki, and A. Hatanaka: Submitted to Agric. Biol. Chem. 

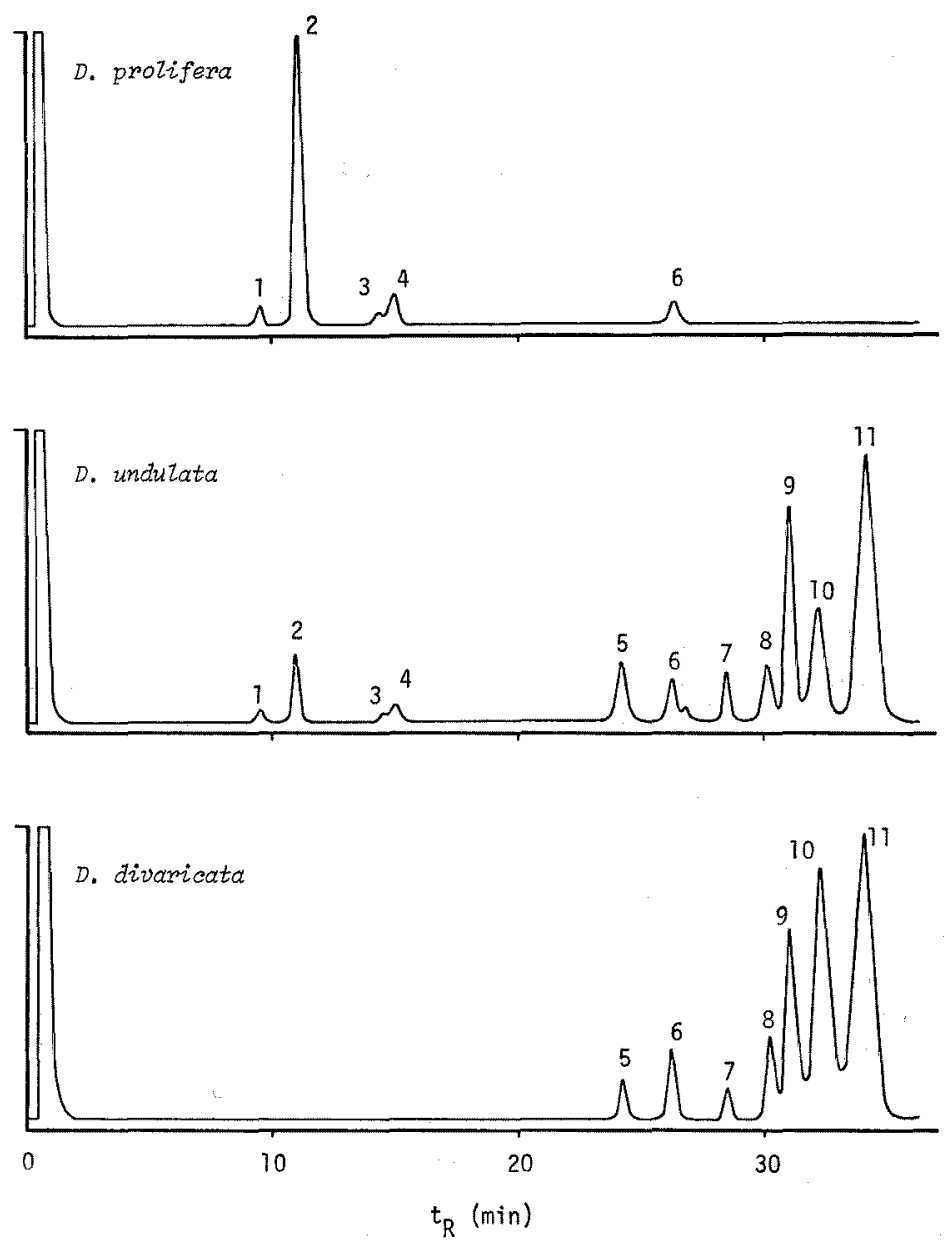

Fig. 1. Gas chromatograms of the odoriferous essential oils from $D$. prolifera, $D$. undulata and $D$. divaricata.

tractant ${ }^{2,3}$, was first confirmed in Japanese species $D$. prolifera and $D$. undulata.

Dictyopterene A $[(+)-(R, R)$-trans-1-(trans-hex$l^{\prime}$-enyl)-2-vinylcyclopropane], dictyopterene B [(-) $(R, R)$-trans- 1 -(trans, cis-hexa-1', 3'-dienyl)- 2 -vinylcyclopropane $]$ and dictyopterene $\mathrm{C}^{\prime}[(-)-(R)-6-$ butylcyclohepta-1,4-diene], had been isolated as "ocean smell" from Hawaiian species $D$. plagiogramma and $D$. australis $^{5,8)}$. Peaks 3, 4, 5 and 7 in Fig. 3 were first identified with dictyopterene $A$, dictyopterene $\mathbf{C}^{\prime}$, ectocarpene and dictyopterene $\mathrm{B}$, respectively, in Japanese species D. prolifera ${ }^{7)}$ and D. undulata by comparison of GLC retention data and mass spectra using authentic samples ${ }^{4) * 8}$.

However, dictyopterene B was not detected by GLC analysis at higher temperature (condition-b) as shown in Fig. 1. The fact suggests that dictyopterene $B$ was thermally converted to the enantiomer of ectocarpene during GLC analysis as shown in Fig. 4. Comparison of gas chromatograms at lower temperature (condition-a) (Fig. 3) of the non-isoprenoids $\mathrm{C}_{11}$-compounds in essential oils from both Dictyopteris, indicated that dictyopterene $\mathrm{A}$ and dictyopterene $\mathrm{B}$ were the major constituents as summarized in Table 2.

The characteristic "ocean smell" of $D$. prolifera consisted of non-isoprenoids $\mathrm{C}_{11}$-compounds, and D. undulata a mixture of the $\mathrm{C}_{11}$-compounds (hydrocarbons) and sesquiterpenes (hydrocarbons).

In striking contrast to $D$. prolifera the constituents of "beach odor" of freshly wet $D$. divaricata was found to be a mixture of sesquiterpenes of 

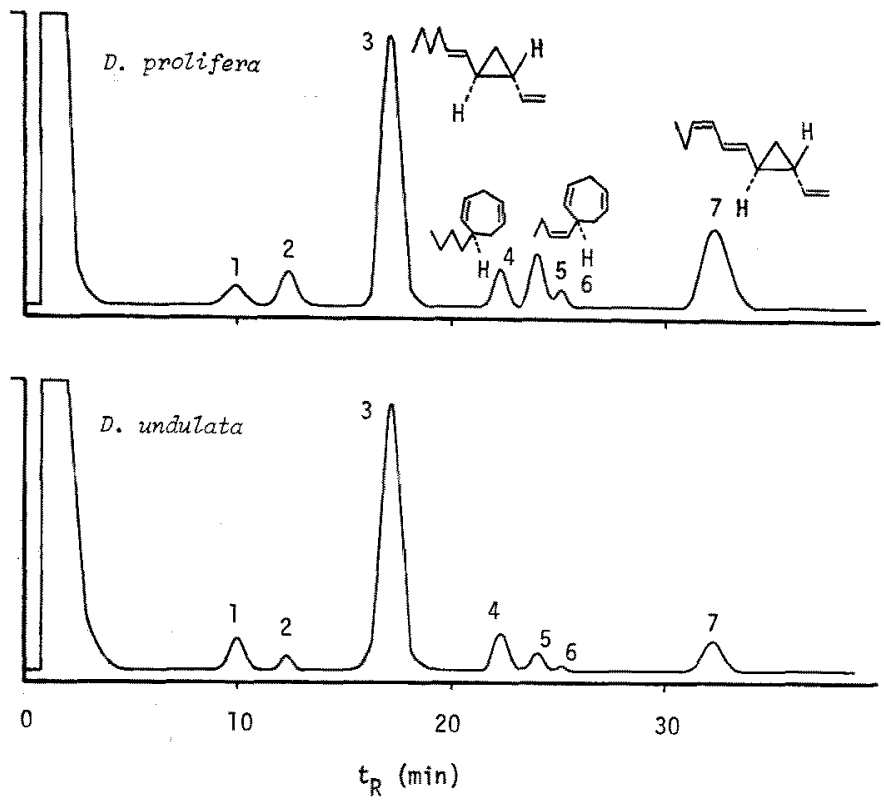

Fig. 2. Gas chromatograms of non-isoprenoids $C_{11}$-compounds in the essential oils of $D$, prollera and $D$. undulata.

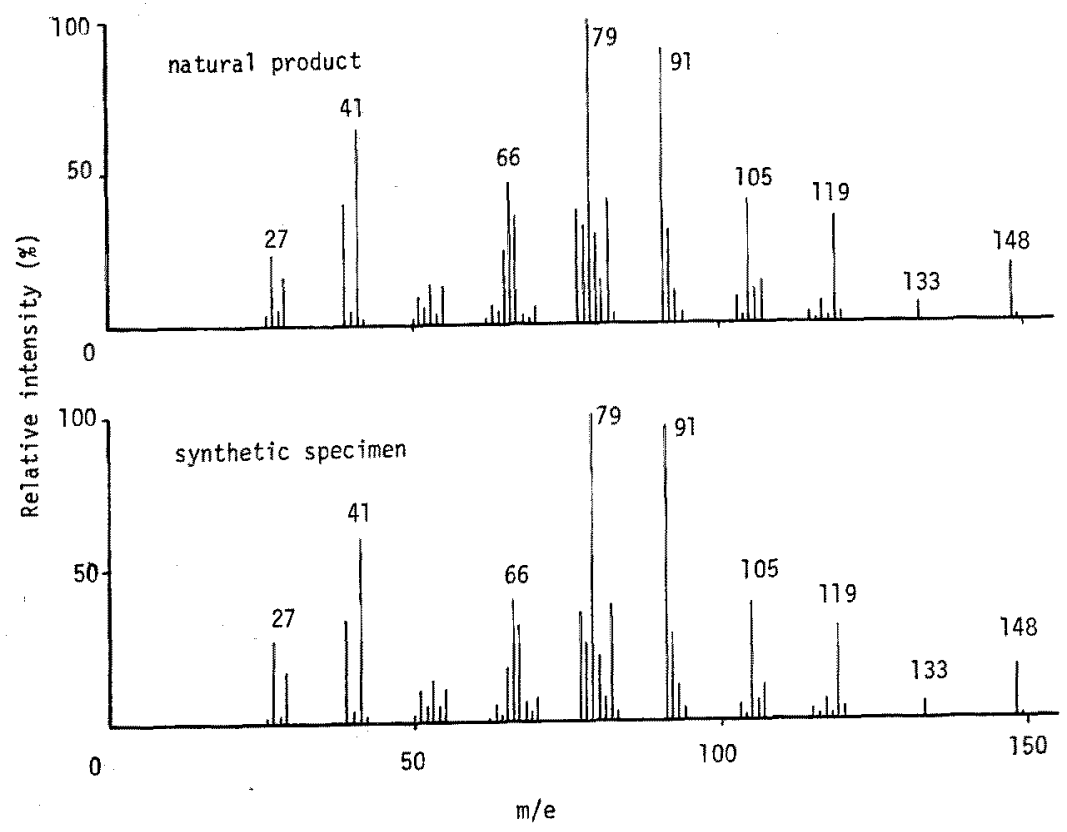

Fig. 3. Mass spectra of ectocarpene. 
Table 1. Constituents of the odoriferous essential oils from $D$. prolifera, $D$, undulata and $D$. divaricata

\begin{tabular}{|c|c|c|c|}
\hline $\begin{array}{l}\text { Peak } \\
\text { No. }\end{array}$ & Components & $\begin{array}{l}\text { MS data } m / e \\
\text { (intensity } \% \text { ) }\end{array}$ & $\underset{t_{R}(\mathrm{~min})}{\mathrm{GLC}^{*}}$ \\
\hline 1 & $\mathrm{C}_{11} \mathrm{H}_{18}$ & $\begin{array}{l}150(16), 93(42), \\
79(100), 67(25), \\
66(45), 41(50), 27(16)\end{array}$ & 9.5 \\
\hline 2 & $\begin{array}{l}\text { Dictyo- } \\
\text { pterene A }\end{array}$ & $\begin{array}{l}150(6), 93(36) \\
79(100), 67(27) \\
66(22), 41(45), 27(19)\end{array}$ & 11.3 \\
\hline 3 & $\begin{array}{l}\text { Dictyo- } \\
\text { pterene } C^{\prime}\end{array}$ & $\begin{array}{l}150(23), 93(70) \\
79(100), 67(20) \\
66(19), 41(37), 27(17)\end{array}$ & 13.8 \\
\hline 4 & Ectocarpene & $\begin{array}{l}148(18), 133(7), \\
119(31), 105(39), \\
91(97), 79(100), \\
66(41), 41(60)\end{array}$ & 14.3 \\
\hline 5 & $\mathrm{C}_{18} \mathrm{H}_{24}$ & $\begin{array}{l}204(10), 161(31), \\
136(83), 121(100), \\
93(85), 41(32) .\end{array}$ & 24.2 \\
\hline 6 & $\mathrm{C}_{15} \mathbf{H}_{90}$ & $\begin{array}{l}210(10), 125(12), \\
97(51), 83(69), \\
69(80), 55(94), \\
53(100), 43(97)\end{array}$ & 26.0 \\
\hline 7 & $\alpha$-Copaene & $\begin{array}{l}204(61), 189(69) \\
105(100), 91(94), \\
43(92) .\end{array}$ & 28.7 \\
\hline 8 & $\beta$-Cubebene & $\begin{array}{l}204(55), 189(38), \\
161(100), 119(47), \\
105(64), 81(32), 41(40) .\end{array}$ & 30.8 \\
\hline 9 & $\mathrm{C}_{15} \mathrm{H}_{24}$ & $\begin{array}{l}204(83), 189(20), \\
161(100), 119(47), \\
105(41), 81(96), 41(90) .\end{array}$ & 32.3 \\
\hline 10 & $\mathrm{C}_{15} \mathrm{H}_{24}$ & $\begin{array}{l}204(83), 189(38) \\
\text { 161(100), 119(40), } \\
105(94), 81(32), 41(90)\end{array}$ & 33.3 \\
\hline 11 & $\delta$-Cadinene & $\begin{array}{l}204(64), 189(38), \\
161(100), 119(32), \\
105(36), 81(57), 41(29)\end{array}$ & 35.9 \\
\hline
\end{tabular}

Table 2. Comparison of constituents in "ocean smell" from D. prolifera and D. undulata

\begin{tabular}{clccc}
\hline \multirow{2}{*}{$\begin{array}{c}\text { Peak } \\
\text { No. }\end{array}$} & Components & \multicolumn{2}{c}{ Peak area $(\%)$} & $\begin{array}{c}\text { GLC* } \\
t_{R}\end{array}$ \\
\cline { 2 - 5 } & & D.prolifera & D.undulata & $(\mathrm{min})$ \\
\hline 1 & $\mathrm{C}_{11} \mathrm{H}_{18}$ & 3 & 3 & 5.5 \\
2 & $\mathrm{C}_{11} \mathrm{H}_{18}$ & 8 & 9 & 5.9 \\
3 & Dictyopterene A & 65 & 69 & 8.1 \\
4 & Dictyopterene $\mathrm{C}^{\prime}$ & 3 & 5 & 11.3 \\
5 & Ectocarpene & 9 & 6 & 12.4 \\
6 & Undecatriene & tr & tr & 13.0 \\
7 & Dictyopterene B & 10 & 9 & 17.4 \\
\hline
\end{tabular}

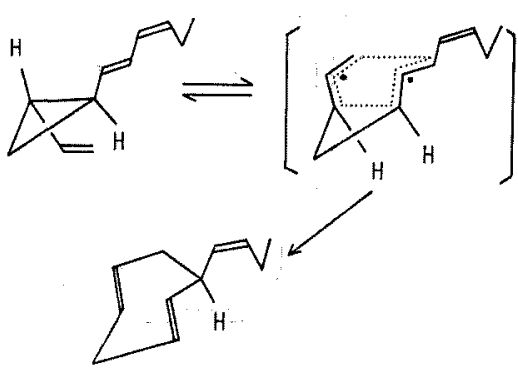

Fig. 4. Rearrangement of dictyopterene $B$ to the enantiomer of ectocarpene.

the cadinene type ${ }^{s)}$ instead of the $\mathrm{C}_{11}$-hydrocarbons, by GLC and mass analysis (Fig. 1 and Table 1).

On the other hand, Moore et al. ${ }^{\theta)}$ reported that in contrast to the Hawaiian species, the species of D. zonarioides $^{10)}$ that grown along the coasts of Lower California, elaborates the sesquiterpenes instead of the $\mathrm{C}_{11}$-compounds.

Further investigation is required to discuss whether or not the remarkable difference of components (non-isoprenoids and sesquiterpenes) between the species of Dictyopteris, depends on the seasonal variation and the growth of the Dictyopteris.

\section{Acknowledgements}

This work was supported in part by grants from the Agricultural Chemical Foundation of Japan and from the Mishima Kaiun Foundation of Japan. The authors wish to thank Professor K. SAKAI, Director of the Institute of Algological Research, Hokkaido University, Muroran, for the facilities during the investigation of $D$. divaricata. The authors also thank Dr. T. OshImA, K. HoNDA and M. NishimurA, Ube Industry, Japan, for GCmass measurement.

\section{References}

1) T. Kajiwara, K. Kodama, and A. Hatanaka: Bull. Japan. Soc. Sci. Fish., 46, 13-15 (1980).

2) D. G. MÜLleR, L. JAENIKE, L. DONIKE, and M. AKINTOBI: Science, 171, 815-817 (1971).

3) J. A. Pettus, JR, and R. E. Moore: J. Amer. Chem. Soc., 93, 3087-3088 (1971).

4) T. Kajiwara, Y. INOUYE, and M. OHNo: Bull. Inst. Chem. Res., 49, 179-199 (1971).

5) R. E. Moore, J. A. Pettus, JR., and M. S. DotY: Tetrahedron Lett., 4789-4790 (1968). 
6) J.A. Petrus, Jr., and R. E. Moore: J. Chem. Soc., Chem. Commun., 1093 (1970).

7) K. Yamada, H. TAN, and H. TATEMATSU: $J$ Chem. Soc., Chem. Commun, 572-573 (1979).

8) T. IRIE, K. YAMAMOTO, and T. MASAMUNE: Bull.
Chem. Soc. Japan, 37, 1053-1055 (1964).

9) R. E. Moore: Accounts Chem. Res., 10, 40-47 (1977).

10) J. J. Sims, W. Fenical, R. M. Wing, and P. C. RADLICK: Phytochemistry, 11, 1161-1163 (1972). 